\title{
Research on Whipping and Jetting Combined Swimming Behavior of Solen strictus Gould
}

\author{
Zhaohui Dong ${ }^{1}$, Shusheng $\mathrm{Bi}^{2}$ and Tian $\mathrm{Liu}^{3, *}$ (D) \\ 1 College of Engineering, Peking University, Beijing 100871, China; zhdong@pku.edu.cn \\ 2 Robotics Institute, Beihang University, Beijing 100191, China; ssbi@buaa.edu.cn \\ 3 Mechanical and Electrical Engineering School, Beijing Information Science and Technology University, \\ Beijing 100192, China \\ * Correspondence: liutian@bistu.edu.cn
}

Citation: Dong, Z.; Bi, S.; Liu, T. Research on Whipping and Jetting Combined Swimming Behavior of Solen strictus Gould. J. Mar. Sci. Eng 2021, 9, 1086. https://doi.org/ 10.3390/jmse9101086

Academic Editor: Dan Tchernov

Received: 2 September 2021

Accepted: 1 October 2021

Published: 5 October 2021

Publisher's Note: MDPI stays neutral with regard to jurisdictional claims in published maps and institutional affiliations.

Copyright: (c) 2021 by the authors. Licensee MDPI, Basel, Switzerland. This article is an open access article distributed under the terms and conditions of the Creative Commons Attribution (CC BY) license (https:// creativecommons.org/licenses/by/ $4.0 /)$.

\begin{abstract}
Solen strictus Gould are mainly cave dwellers, using their axe feet to dig caves. The Solen strictus Gould also exhibit escape-swimming behavior when food, environment, and so on changes. In this paper, Solen strictus Gould were captured on a high-speed camera as they escaped, and it was found that the Solen strictus Gould whipped while the water spout between the axe foot and the mantle sprayed water outwards. The combined propulsion of these two methods allows the Solen strictus Gould to advance rapidly in a short time. It is calculated that the swimming speed of razor clams is positively correlated with their size and that the adult Solen strictus Gould can travel up to 12 times their body length per second. This study enriches the data on the behavioral characteristics of Solen strictus Gould and is of interest regarding Solen strictus Gould in artificial farming, marine fishing, offshore ecological restoration, and underwater bionic robot development.
\end{abstract}

Keywords: Solen strictus Gould; axe foot; swimming; whipping and jetting

\section{Introduction}

The ocean occupies $70.8 \%$ of the total surface area of the earth and contains rich resources. The ocean is the place of origin of life. From the perspective of biological evolution, after hundreds of millions of years of evolution, the aquatic organisms that have survived to this day have undergone a natural selection of the best and the worst, and their ability to move in the water has a very high bionic value. Exploring the motion mechanisms of underwater organisms and applying them to the study of underwater bionic robots could lead to the development of underwater bionic robots with better motion performance. This can help humans to develop and utilize marine resources and expand human activities and space in the ocean. Bionic underwater robots have extremely important applications in the exploration and development of marine resources, marine military security, and monitoring and protection of marine ecological environment [1,2]. The research on underwater bionic robots is also a current research hotspot. Compared with biological prototypes, the current motion capabilities of underwater robots are still dwarfed. One of the important reasons comes from the difference in propulsion mechanisms. Accurately grasping and using the movement mechanisms of underwater creatures is a necessary scientific way to fundamentally improve the efficiency and function of bionic robots.

There are many types of underwater creatures, and the movement patterns of various kinds of creatures in water are different. The wave-shaped swing propulsion movement of fish is the earliest and most studied, and it is also the most extensive movement method of underwater creatures. Which mainly relies on the lateral twisting of the body, which swings back and forth and propagates the movement from the front to the back in the manner of shear waves [3]. At present, researchers at home and abroad have conducted a lot of research on the propulsion mechanism of fish from theoretical analysis, numerical simulation, experimental observation, and other aspects [4-7]. Underwater creatures 
represented by jellyfish, squid, and scallops squeeze the water backwards through the cavity inside the body, and use the conservation of momentum to generate thrust to move the body forward [8-12]. There are also underwater creatures, such as flying fish, which have the ability to move in both air and water. They can sneak freely from the water, then slide to the water surface, fly away from the water surface, and efficiently convert between the two media [13]. In addition, there are rotating propulsion modes of underwater microorganisms represented by flagellates [14,15]; jumping movement modes of whales, dolphins, frogs, and other creatures [16]; and crawling or paddling movement modes of turtles, shrimps, and crabs $[17,18]$. Field observation, morphological parameter measurement, and motion mechanism analysis of these movement methods have important research significance for bionics.

Razor clams are predominantly cave-dwelling. Through the opening and closing of their shell and their axe-foot movement, they can dig caves on the sandy beaches and rise and fall in the caves. There are many research reports on the excavation of razor clams. In addition to digging, some types of razor clams (for example Solen grandis Dunker, Solen strictus Gould, Ensis Siliqua, Siliqua Patula, Cultellus scalprum Gould, and so on) [19] can also perform pop-up swimming [20]. This is a very unique way of movement, and razor clams have achieved rapid swimming in this way. At present, there has been bionic development of the digging function of razor clams. Winter et al. have devised a RoboClam for underwater environmental monitoring and submarine cable fixation [21,22]. However, there have been few reports on the study of the unique swimming movement of bamboo razor clams. The digging and swimming behavior of razor clams are very characteristic, which provides a very good reference for the research of bionic robots.

In this paper, the escape swimming process of Solen strictus Gould was observed by a high-speed camera, and the escape swimming of razor clams of different sizes was observed in detail. Then the swimming speed and acceleration of the razor clam were obtained by frame-by-frame analysis. Through the trace point method, the swing trajectory of the axe foot is obtained, and the swing trajectory is fitted with MATLAB. The research enriches the razor clam behavior data and has important reference value for the development of an underwater bionic robot.

\section{Materials and Methods}

\subsection{Solen strictus Gould}

The Solen strictus Gould used in the experiment were collected from the offshore beach of Grape Island in Nandaihe District, Qinhuangdao City, Hebei Province. The Solen strictus Gould without any damage to the shell were picked, and then were put in a fish tank with sand and sea water, and were brought back to the laboratory, and the oxygen supply was maintained during the period. Razor clams can be brought to the laboratory to start the experiment and maintain the oxygen supply during the experiment. Usually, the razor clam is not sensitive to seawater temperature, $10-30{ }^{\circ} \mathrm{C}$ range can be normal survival. Test razor clam specifications: Adult Gould (8), shell length $(10 \pm 0.5) \mathrm{cm}$, body weight $(45 \pm 0.5) \mathrm{g}$; Juvenile Solen strictus Gould (8), shell length $(5.3 \pm 0.5) \mathrm{cm}$.

\subsection{Swimming Observation Experimental Procedures}

A transparent water tank with a size of $100 \times 30 \times 30 \mathrm{~cm}$ was made of acrylic plastic material. A layer of sand was stacked in the tank with a thickness of $1 \mathrm{~cm}$ and then placed in seawater at a depth of $15 \mathrm{~cm}$. The dissolved oxygen in the seawater was greater than about $0.6 \mathrm{mg} / \mathrm{L}$. A digital camera (FASTCAM Mini UX50, Photron Corporation, Tokyo, Japan) was installed above the tank to take a swimming video of the long razor clam. The height from the tank to the camera is $1.5 \mathrm{~m}$. The experimental setup is shown in Figure 1. 


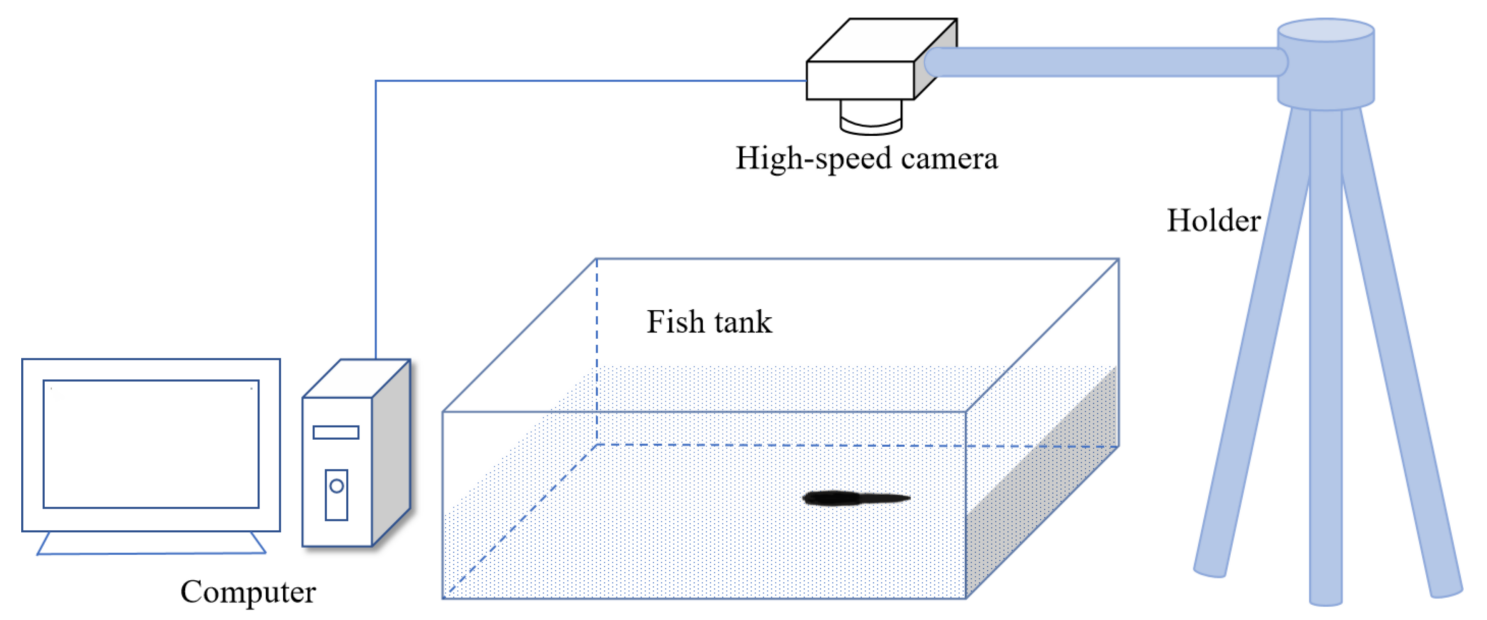

Figure 1. Diagram of the experiment device.

The razor clams were taken out of the water for $10 \mathrm{~s}$ then put into the test tank to make it feel threatened so that it can escape. Due to environmental changes, the razor clams can be stimulated to escape. The escaped behavior of the razor clams would be photographed with a high-speed camera. Two experiments were conducted on the adult Solen strictus Gould and juvenile Solen strictus Gould (See Supplementary Materials).

\subsection{Swimming Speed Analysis}

The captured videos were decomoposed frame by frame to extract the typical movement process, so as to analysis the escape swimming speed, acceleration, and whipping swinging trajectory of Solen strictus Gould. The axe foot is the main functional organ of the whip ejection propulsion of Solen strictus Gould.

We manually marked the position of the point where the Solen strictus Gould axe foot meets the shell. The moving distance $d_{i}$ between two adjacent frames can be obtained. The time interval $t$ between the two adjacent frames is known. Therefore, the speed $V_{i}=d_{i} / t$ can be obtained. Furthermore, the acceleration $a=\left(a_{1}+\ldots+a_{n)} / n(n\right.$ is the total number of frames, $i=1,2, \ldots, n-1)$ can also be obtained. The calculated average value of all speeds from rest to the maximum speed $\left(V_{\max }\right)$ is the rush speed, and the average value of all speeds from maximum speed $\left(V_{\max }\right)$ to stop is the sliding speed.

\subsection{Motion Trajectory Analysis Fitting and Analysis}

The video of the razor clam escaping swimming captured by the high-speed camera is decomposed by MATLAB software to obtain a frame-by-frame image. The position coordinates of manually marked points are programmed to be obtained based on the positional relationship of the image pixel points. The coordinate data of these points were obtained by $\mathrm{C}++$ programming. These coordinate data were processed and fitted using MATLAB software to obtain the equations of the axe foot's trajectory and plot the related curves.

\subsection{Histological Anatomical Observation Experimental Procedures}

In order to explore the physiological mechanism of escape and swimming of Solen strictus Gould, histological anatomical observation and micro-morphological observation of axe foot were carried out. After shooting the video, a scalpel was used to cut off the closed shell muscle of the fresh long razor clam. Furthermore, the muscle of the axe foot was split, and the muscle tissue of the axe foot was collected. 


\section{Results}

\subsection{Whipping and Jetting Combined Swimming Processes}

As is shown in Figure $2 a, b$ is that the partial pictures extracted from the high-speed video and the corresponding moments of the pictures. When the Solen strictus Gould started to swim, the axe foot extended out of the shell and gradually bent to one side, meanwhile, the length of axe foot gradually extended. During this time, the speed of Solen strictus Gould is basically unchanged. When the axe foot reached half of its maximum extension length, it began to swing suddenly to the other side like a whip. During the whiplash, the length of the axe foot is still elongating. When the axe foot swings to the same direction as the direction of the shell, it begins to shrink into the shell. At this time, the Solen strictus Gould begins to glide, and the axe foot and the shell are kept in the same straight line to reduce swimming resistance and increase swimming distance.

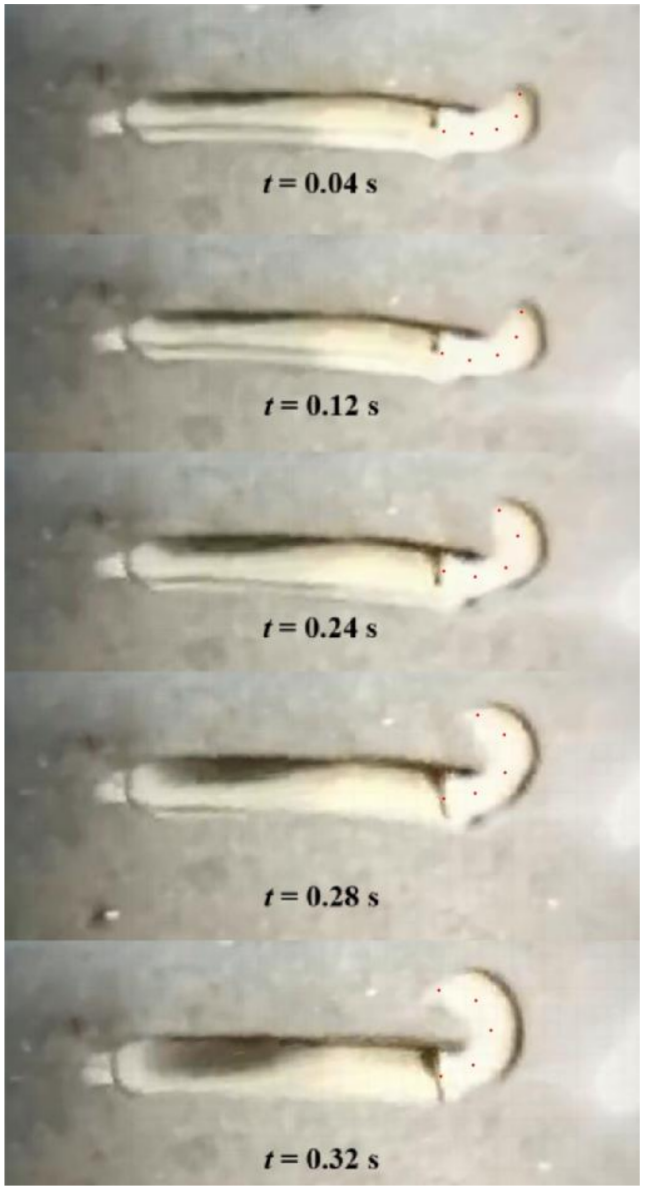

(a)

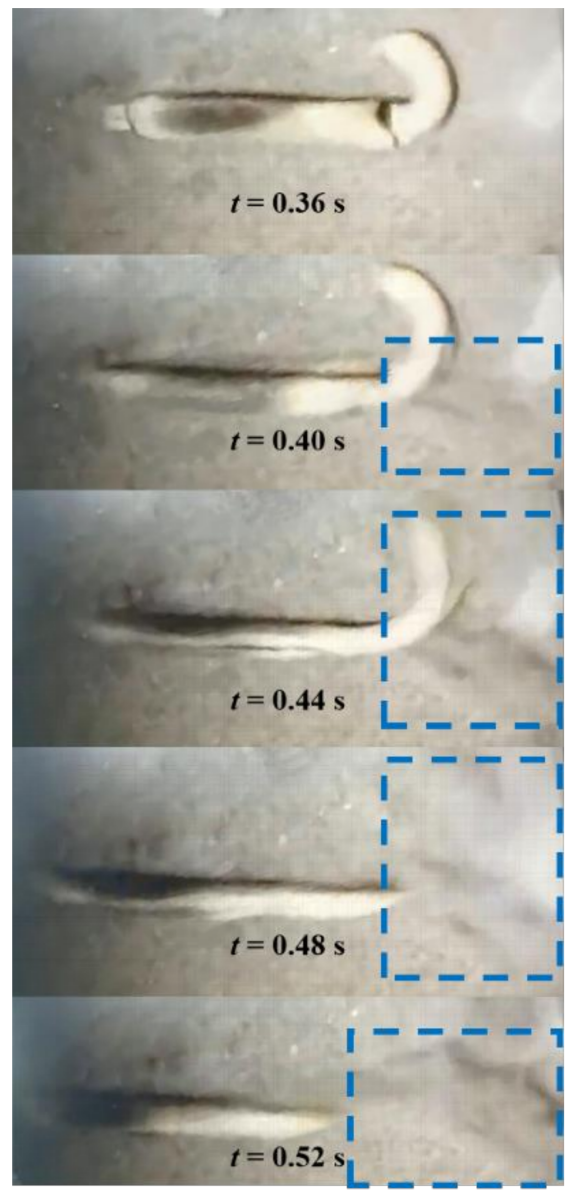

(b)

Figure 2. The whipping and jetting combined swimming process of adult Solen strictus Gould. (a) shows the result of the axe foot deformation movement. (b) shows the water spraying process during the Solen strictus Gould's swimming.

By carefully observing subsequent photos of the adult Solen strictus Gould movement, it can be seen that the position of the object changes in an unexpected way. In the sequence of photos in Figure 2a, the rotation of the adult Solen strictus Gould by 90 degrees relative to the longitudinal axis is clearly visible. When increasing the length of the axe foot, the double shell rotates so that the opening between the shells is under the object.

We observed the Solen strictus Gould spraying water by laying sand on the bottom of the tank. The turbidity appears on the surface of the water in the blue frame marked in Figure 2b. the Solen strictus Gould will spray water backward when the axe foot starts to swing quickly, and the water in the mantle will squeeze out further when the axe foot 
contracts. The fast water spray speed will speed up the movement of the Solen strictus Gould, which is another propulsion mode of the Solen strictus Gould-namely, the jet propulsion. The axe foot twists the Solen strictus Gould. At the time of muscle contraction, water flows from the inside of the shell halves outwards, but down, under the Solen strictus Gould, lifting it above the sand surface. This reduces drag when swimming.

Through the combined propulsion of the two modes, the Solen strictus Gould can quickly move to a relatively long distance in a short time. When the gliding speed of the Solen strictus Gould has dropped to a certain level or is rest, the above process will be repeated again. When the Solen strictus Gould needs to turn, the water spout between its mantle and the axe foot sprays water outward, and the axe foot slowly extends and bends to act as a rudder.

\subsection{Swimming Speeds}

By marking red points on the frame-by-frame images, as it is shown in Figure 2a, the sprint speed and acceleration of adult Solen strictus Gould and juvenile Solen strictus Gould is shown in Figures 3 and 4. The blue 'pentagram line' shows the velocity and the red 'dotted line' shows the acceleration. Furthermore, the calculated maximum speed, rushing speed, gliding speed, and acceleration time of adult Solen strictus Gould and juvenile Solen strictus Gould are shown in Table 1.

Table 1. Speed and acceleration time of Solen strictus Gould.

\begin{tabular}{cccc}
\hline Speeds & Speed Types & Adult Solen strictus Gould & Juvenile Solen strictus Gould \\
\hline \multirow{2}{*}{ Maximum Speed } & Relative values $/\left(\mathrm{BL} \cdot \mathrm{s}^{-1}\right)$ & 11.8 & 8.7 \\
& Absolute values $/\left(\mathrm{cm} \cdot \mathrm{s}^{-1}\right)$ & 118 & 45.6 \\
\hline \multirow{2}{*}{ Rushing Speed } & Relative values $/\left(\mathrm{BL} \cdot \mathrm{s}^{-1}\right)$ & 4.8 & 3.5 \\
& Absolute values $/\left(\mathrm{cm} \cdot \mathrm{s}^{-1}\right)$ & 48 & 18.5 \\
\hline \multirow{2}{*}{ Sliding Speed } & Relative values $/\left(\mathrm{BL} \cdot \mathrm{s}^{-1}\right)$ & 4.9 & 5.8 \\
& Absolute values $/\left(\mathrm{cm} \cdot \mathrm{s}^{-1}\right)$ & 49 & 30 \\
\hline
\end{tabular}

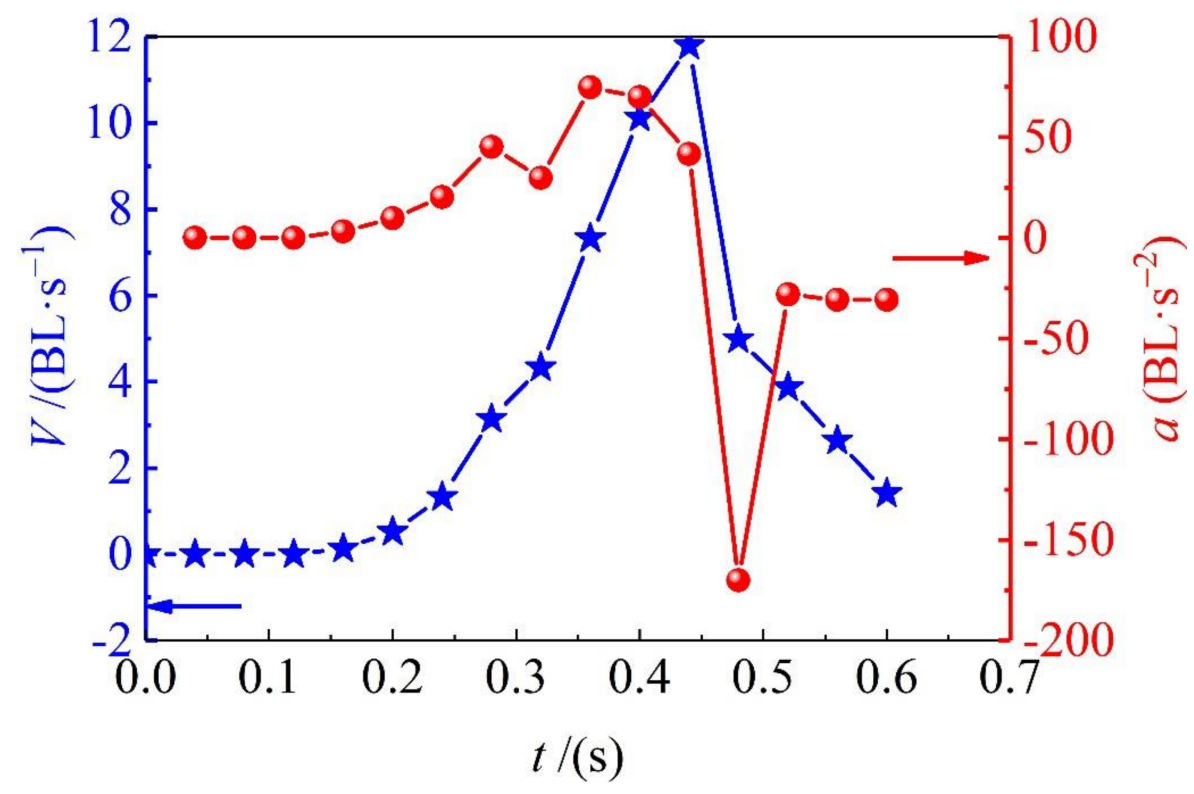

Figure 3. Sprint speed and acceleration of adult Solen strictus Gould. 


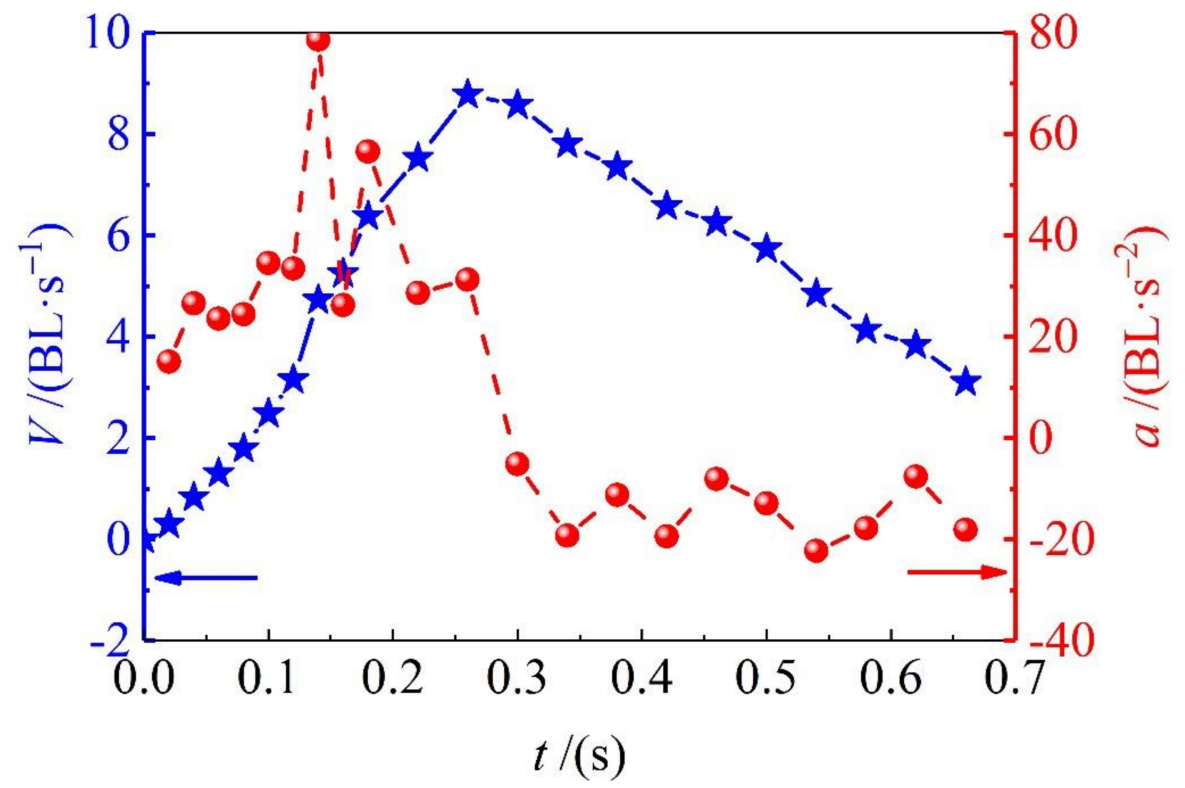

Figure 4. Sprint speed and acceleration of juvenile Solen strictus Gould.

\subsection{Trajectory of the Solen strictus Gould Axe Foot}

According to Figure 2a,b, the Solen strictus Gould axes bend into a circular shape during the whipping process, similar to the C-shaped start (escape) of fish [23].

A typical image was selected, and the intersection of the center line of the adult Solen strictus Gould axe foot and the dividing line between the axe foot and the shell was chosen as the origin to establish a coordinate system with the body. The center line of the axe foot was uniformly traced (as shown in Figure 2a) to obtain the center line trajectory of the axe foot in each frame, and then the equation of the curvature $k$ of the axe foot was fitted according to the circular equation (as shown in Equation (1) and Equation (2)). The coefficient of determination of the fit $R^{2}=0.915$.

$$
\begin{gathered}
R(t)=\frac{R_{0}}{k(t)} \\
k(t)=1.24-\frac{1.6}{1+10^{t \cdot S_{K}^{1}}}-\frac{1}{1+10^{(c-t) \cdot S_{K}^{2}}}
\end{gathered}
$$

$R_{0}=0.0134 \mathrm{~m}$ is the minimum radius of curvature of the Solen strictus Gould axe foot bend, $k(t)$ is the curvature change function of the Solen strictus Gould axe foot curve, $C=0.44$ is the length coefficient of the Solen strictus Gould axe foot whip, $S_{K}^{1}=1.7$ is the length coefficient of the Solen strictus Gould axe foot up swing (whip preparation phase), $S_{K}^{2}=20.2$ is the length coefficient of the Solen strictus Gould axe foot back swing (whip phase).

The expansion and contraction of the Solen strictus Gould axe foot in the whipping process was obtained by fitting the expansion and contraction law as shown in Equation (3), with the coefficient of determination $R^{2}=0.896$.

$$
L(t)=\frac{3.992}{e^{\left(\frac{t-0.4828}{0.07368}\right)^{2}}}+\frac{4.48}{e^{\left(\frac{t-0.3133}{0.3167}\right)^{2}}}
$$

Fitted image of the adult Solen strictus Gould axe foot whip trajectory according to Equation (3). As is shown in Figure 5. 


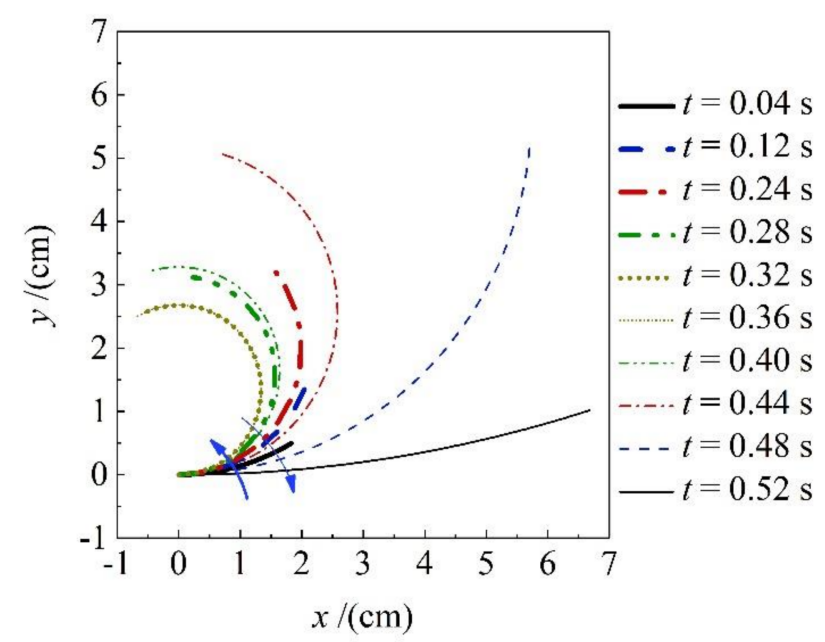

Figure 5. Fitted image of the trajectory of axe foot whip of the adult Solen strictus Gould.

When the C-shaped retractable whip of the Solen strictus Gould axe foot is moving, the axe foot extension length is the product of the bending angle of the axe foot and the bending radius, so the axe foot $\mathrm{C}$-shaped arc can be plotted against time and the axe foot extension length against time based on the measured data, as shown in Figure 6, the blue pentagram points are the axe foot length values at different moments, and the red dots are the corresponding circle center angles at the same moment. The trend of the curve shows that when the Solen strictus Gould axe foot swings to the corresponding angle of $90^{\circ}$, the axe foot extension length reaches its maximum value, and the tangential direction of the end of the axe foot is perpendicular to the axe foot shell direction at this time. Combined with the observation of the test swim of the Solen strictus Gould, the Solen strictus Gould began to spray water at $0.35 \mathrm{~s}$, when the axe foot bending curvature maximum, the maximum angle of the circle center $\left(225^{\circ}\right)$.

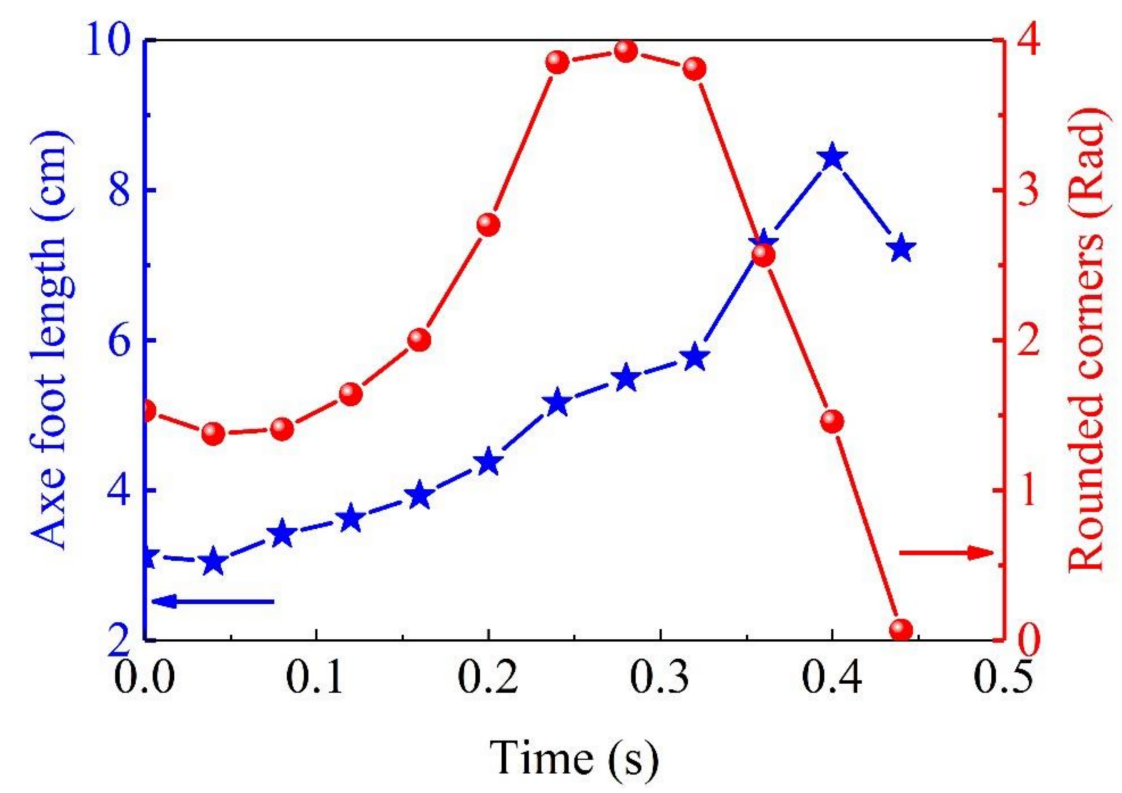

Figure 6. Variation curve of axe foot length and rounding angle of the adult Solen strictus Gould.

\subsection{Structures of the Mantle}

Solen strictus Gould are bivalve mollusks, so their structure is similar to bivalve mollusks. The anatomical image of Solen strictus Gould is shown in Figure 7. The gap between the axe foot and the mantle forms a water spout. The shape of the water spout is ' $\mathrm{V}$ '. The Solen strictus Gould shrink or swing the axe foot and the edge of the mantle 
shrink according to the situation during the water spraying process to change the area of the water spout.

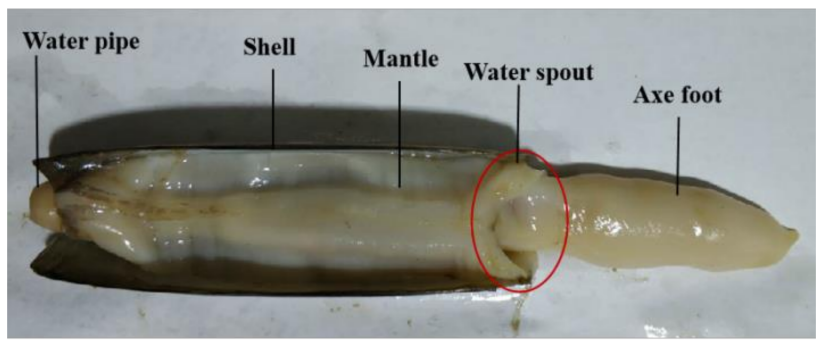

Figure 7. Anatomical image of the Solen strictus Gould.

The muscular structure of the mantle of the Solen strictus Gould is a muscular hydrostatic skeleton structure, and its volume remains unchanged during the process of contraction or extension. The thickness of the mantle is about $1 \mathrm{~mm}$, which is different according to the size of the Solen strictus Gould. In addition, the mantle of artificially cultivated Solen strictus Gould is thicker.

The mantle is a milky white translucent film that covers the entire body of Solen strictus Gould. The mantle fits the shell of the Solen strictus Gould. Like the shell of the Solen strictus Gould, the cavity between the left and right mantles is called the mantle cavity. At the front end (axe foot end) of Solen strictus Gould, there is an oval opening in the mantle for the axe foot to extend in and out of the shell. The rear end of the mantle (the water pipe end) is well-developed and differentiated to form two water pipers (the inlet pipe and outlet pipe). There are muscle bundles corresponding to the anterior and posterior closed shell muscle, which is interspersed around the inner and outer edges of the mantle.

\section{Discussion}

The Solen strictus Gould generally live-in mud and sand. When environmental factors such as food and salinity change drastically, they will drill out of the cave and escape through the combined method of axe foot ejection and water spray to find a more suitable habitat. In addition, the Solen strictus Gould generally choose to dig drill holes to avoid danger, but when the Solen strictus Gould cannot escape through excavation, they will choose swimming. This study, for the first time, observed the escape swimming behavior of the Solen strictus Gould.

Through our observation, it was found that when the Solen strictus Gould escapes, its axe foot will whip and swing, and the water spout between the axe foot and the mantle will spray water outward. Through this combined advancement of these two methods, the Solen strictus Gould can quickly advance in a short time. The Solen strictus Gould has two places to drain away water, that is the water outlet and the water spout between the axe foot and the mantle. There are two ports on the water pipe, one is the water outlet and the other is the water inlet. When the closed shell muscle is in a slack state, the mantle cavity expands, and seawater flows into the mantle cavity through the water inlet. At this time, the lips will collect food in the seawater, and the gills will breathe, and then the seawater passes through the gap between the left and right gills. Excrement is discharged from the body through the water outlet. The Solen strictus Gould draining through the water outlet can also push the Solen strictus Gould to swim, but the provided power is little. It would move very slowly by this method. However, the power provided by the external jet drainage through the opening of the mantle is relatively large. When the Solen strictus Gould escapes, the closed shell muscle contract and the volume of the mantle cavity decreases sharply. The water in the mantle cavity will jet outward through the water spout between the axe foot and the mantle.

As is known, the jet propulsion is the main propulsion method when they escape or migrate for clams, scallops, and other bivalve molluscs [24-27]. This type of swimming is a 
common method of propulsion in shellfish and underwater mollusks. However, the jet propulsion of the Solen strictus Gould is not the main propulsion method for swimming. The whipping of the axe foot actually is the main way to promote the rapid swimming of the Solen strictus Gould.

It can be seen from the swimming speed results that the sliding speed is related to the fluid resistance. The body shape of the Solen strictus Gould is small and the resistance is also small. The maximum rushing speed is related to the body shape. The body shape is large and the speed is fast. It is known, from our analysis, that the maximum acceleration of the adult Solen strictus Gould is $74.8 \mathrm{BL} / \mathrm{s}^{2}\left(747.5 \mathrm{~cm} / \mathrm{s}^{2}\right)$, and the maximum acceleration of the juvenile Solen strictus Gould is $78.6 \mathrm{BL} / \mathrm{s}^{2}\left(408.7 \mathrm{~cm} / \mathrm{s}^{2}\right)$, which means that the acceleration of swimming of the Solen strictus Gould is not related to body shape. The whiplash of the axe foot can provide a powerful motive force for the movement of the Solen strictus Gould. The rushing speed of adult the Solen strictus Gould can reach $48 \mathrm{~cm} / \mathrm{s}$, which is close to the maximum stable swimming speed of squid [9]. The maximum speed can reach $11.8 \mathrm{BL} / \mathrm{s}(118 \mathrm{~cm} / \mathrm{s})$, surpassing most cephalopod underwater molluscs, which is completely different from people's understanding of the slow speed of shellfish.

Therefore, the propulsion efficiency of the combined swimming mode of whipping and jetting is high, which has important reference value for the propulsion mode design of the underwater bionic robot. The special form of movement of the bamboo Solen strictus Gould and the unique structure of its axial foot is important for the development of underwater soft bionic robots.

The whip propulsion mode of the Solen strictus Gould's axe foot is the main power source of the Solen strictus Gould's escape. The whip propulsion mode of the Solen strictus Gould axe foot is the main source of power for the Solen strictus Gould to escape and swim. The design of the bionic axe foot is therefore the core of the bionic razor clam robot. The jet propulsion makes the Solen strictus Gould's swimming flexibility greatly enhanced, so the bionic jet design is an important part of the bionic razor clam robot. The bionic axe foot design is based on a study of the Solen strictus Gould axe foot whip. The bionic axe foot design is derived from the imitation of the Solen strictus Gould's axe foot whip and retractable motion form and soft body structure. The drive form of the Solen strictus Gould composite mode drive is unique and useful for exploring the development of new propulsion modes for underwater razor clam robots. The axe-foot design is derived from the mimicry of the Solen strictus Gould axe-foot whip and retract motion form and soft body structure is derived from the variable volume muscular hydrostatic skeleton of the axolotl. The characteristics of axolotls can also provide useful references for the design of soft body structures and materials.

\section{Conclusions}

In this paper, we observe the behavior of the whiplash ejection of the Solen strictus Gould, and superficially explore the physiological mechanism of the behavior. The Solen strictus Gould is a compound propulsion mode when it escapes and swims. The whipping of the axe foot is the main way, meanwhile, the water spout between the axe and the mantle will spray outward. The instantaneous speed of escaped can reach $12 \mathrm{BL} / \mathrm{s}$ $(118 \mathrm{~cm} / \mathrm{s})$, the average speed is $50 \mathrm{~cm} / \mathrm{s}$, and the maximum acceleration can reach $78 \mathrm{BL} / \mathrm{s}^{2}$. This shows that the efficiency of this form of movement is very high, which is of great reference value for the study of the driving mode of underwater bionic robots. The research in this paper enriches the razor clam behavior data and has certain reference value for the artificial cultivation of the Solen strictus Gould, marine fishing, and restoration of the offshore ecological environment.

In this paper, the rolling behavior of the Solen strictus Gould during swimming was not observed in detail, which needs further study. 
Supplementary Materials: The following are available online at https:/ / www.mdpi.com/article/10 .3390/jmse9101086/s1, Video S1: jmse-1386082-supplementary.avi.

Author Contributions: Z.D. and T.L.; methodology, Z.D. and T.L.; investigation, T.L.; data curation, Z.D.; writing—original draft preparation, Z.D. and T.L.; writing—review and editing, Z.D., T.L. and S.B.; supervision, S.B.; funding acquisition, S.B. All authors have read and agreed to the published version of the manuscript.

Funding: This research received no external funding.

Institutional Review Board Statement: Not applicable.

Informed Consent Statement: Not applicable.

Data Availability Statement: The data used to support the findings of this study are included within the article.

Acknowledgments: Thanks for the administrative and technical support from the Robotics Institute of Beihang University.

Conflicts of Interest: The authors declare no conflict of interest.

\section{References}

1. Low, K.H. Current and Future Trends of Biologically Inspired Underwater Vehicles. In Proceedings of the Defense Science Research Conference and Expo (DSR), Singapore, 3-5 August 2011; pp. 1-8.

2. Li, T.; Li, G.; Liang, Y.; Cheng, T.; Yang, X.; Huang, Z. Review of materials and structures in soft robotics. Chin. J. Theor. Appl. Mech. 2016, 48, 756-766.

3. Peng, X. Research status and development trend of underwater robots. Robot Technol. Appl. 2004, 4, 44-47.

4. Borazjani, I.; Sotiropoulos, F. Numerical investigation of the hydrodynamics of anguilliform swimming in the transitional and inertial flow regimes. J. Exp. Biol. 2009, 212, 576-592. [CrossRef]

5. Roth, E.; Sponberg, S.; Cowan, N. A comparative approach to closed-loop computation. Curr. Opin. Neurobiol. $2014,25,54-62$. [CrossRef]

6. Shoele, K.; Zhu, Q. Leading edge strengthening and the propulsion performance of flexible ray fins. J. Fluid Mech. 2012, 693, 402-432. [CrossRef]

7. Zhang, W.; Yu, Y.; Tong, B. Prediction of mechanical properties of fish muscle in vivo during steady swimming. Chin. J. Theor. Appl. Mech. 2014, 46, 619-625.

8. McHenry, M.J.; Jed, J. The ontogenetic scaling of hydrodynamics and swimming performance in jellyfish (Aurelia aurita). J. Exp. Biol. 2003, 206, 4125-4137. [CrossRef] [PubMed]

9. Anderson, E.J.; Grosenbaugh, M.A. Jet flow in steadily swimming adult squid. J. Exp. Biol. 2005, 208, 1125-1146. [CrossRef] [PubMed]

10. Stewart, W.J.; Bartol, I.K.; Krueger, P.S. Hydrodynamic fin function of brief squid, Lolliguncula brevis. J. Exp. Biol. 2010, 213, 2009-2024. [CrossRef]

11. Cheng, J.-Y.; Demont, M.E. Hydrodynamics of scallop locomotion: Unsteady fluid forces on clapping shells. J. Fluid Mech. 1996, 317, 73-90. [CrossRef]

12. Salazar, R.; Fuentes, V.; Abdelkefi, A. Classification of biological and bioinspired aquatic systems: A review. Ocean Eng. 2017, 148, 75-114. [CrossRef]

13. Gao, A.; Techet, A.H. Design considerations for a robotic flying fish. In Proceedings of the OCEANS'11 MTS/IEEE KONA, Waikoloa, HI, USA, 19-22 September 2011.

14. Monger, B.C.; Landry, M.R. Direct-interception feeding by marine zooflagellates: The importance of surface and hydrodynamic forces. Mar. Ecol. Prog. 1990, 65, 123-140. [CrossRef]

15. Dölger, J.; Bohr, T.; Andersen, A.P. An analytical model of flagellate hydrodynamics. Phys. Scr. 2017, 92, 044003. [CrossRef]

16. Zhang, W. Research on the Frog Inspired Robot and Its Swimming Trajectory Planning; Harbin Institute of Technology: Harbin, China, 2017.

17. Chen, X.; Wang, L.-Q.; Ye, X.-F.; Wang, G.; Wang, H.-L. Prototype development and gait planning of biologically inspired multi-legged crablike robot. Mechatronics 2013, 23, 429-444. [CrossRef]

18. Omori, M.; Ohta, S. The use of underwater camera in studies of vertical distribution and swimming behaviour of a sergestid shrimp, Sergia lucens. J. Plankton Res. 1981, 3, 107-121. [CrossRef]

19. Chen, P.; Ye, Q.; Li, B. The preliminary on the biology of Cultellum Scalprum (Golud) II. distioh and Living-habits. J. Jimei Univ. (Nat. Sci.) 1986, 01, 46-57.

20. Akira, A. The Biokinetics of Flying and Swimming. Springer: Tokyo, Japan, 1992.

21. Isava, M.; Winter, V.A.G. An experimental investigation of digging via localized fluidization, tested with roboclam: A robot inspired by atlantic razor clams. J. Mech. Des. 2016, 138, 125001. [CrossRef] 
22. Winter, A.G.; Deits, R.L.H.; Dorsch, D.S.; Slocum, A.H.; E Hosoi, A. Razor clam to RoboClam: Burrowing drag reduction mechanisms and their robotic adaptation. Bioinspiration Biomim. 2014, 9, 036009. [CrossRef]

23. Chen, H.; Zhu, C.; Yin, X.; Xin, X. Kinematic Characters on C-turn Swimming of Fish-like Robot. Chin. J. Appl. Mech. 2008, 25, 229-234.

24. Wang, Z.; Hang, G.; Wang, Y.; Li, J. Swimming mechanism of squid/cuttlefish and its application to biomimetic underwater robots. Chin. J. Mech. Eng. 2008, 44, 1-9. [CrossRef]

25. Bartol, I.K.; Patterson, M.R.; Mann, R. Swimming mechanics and behavior of the shallow-water brief squid Lolliguncula brevis. J. Exp. Biol. 2001, 204, 3655-3682. [CrossRef] [PubMed]

26. Santhanakrishnan, A.; Dollinger, M.; Hamlet, C.L.; Colin, S.; Miller, L.A. Flow structure and transport characteristics of feeding and exchange currents generated by upside-down Cassiopea jellyfish. J. Exp. Biol. 2012, 215, 2369-2381. [CrossRef] [PubMed]

27. Imamura, K.; Tsuruta, D.; Tsuchisaka, A.; Mori, T.; Ohata, C.; Furumura, M.; Hashimoto, T. Anaphylaxis caused by ingestion of jellyfish. Eur. J. Dermatol. EJD 2013, 23, 392-395. [CrossRef] [PubMed] 